\title{
Investigation and Analysis of Changqing Campus of Wuhan Polytechnic University Based on Traffic Distribution
}

\author{
Huiyan Zhao \\ School of Civil Engineering and Architecture \\ Wuhan Polytechnic University ${ }^{1}$ \\ ATA Architectural Design Ltd. ${ }^{2}$ \\ Wuhan, China \\ e-mail: 774625545@qq.com
}

\begin{abstract}
Traffic distribution is extremely uneven in Changqing campus of Wuhan Polytechnic University. To find out how exactly unbalanced it is and how to remedy this situation, investigation and questionnaire were carried out. Here only focus on the traffic investigation which was adopted eight observation points, including four entrances to the campus and four points in the campus' main roads. They were observed for 15 days and recorded 15 minutes for the interval from 7:30 am to 9:00 pm. Then line graphs are made to contrast. The traffic has been proved to be unbalanced among four gates or even in the main roads. A characteristic in the places with heavy traffic flow is in common that the traffic fluctuation is highly related to students' class schedule. That is, traffic usually reaches its peak at the time before and after classes, and falls rapidly during classes. The outcomes are analyzed from two respects, one is the concentration of main functional areas, and the other is the large green space without attraction to people. Finally, some suggestions for the strategy of campus' reconstruction planning are put forward to improve these aspects.
\end{abstract}

Keywords--traffic investigation; traffic distribution; campus planning; function; green space

\section{INTRODUCTION}

Campus planning and construction cannot be once and for all. Many colleges and universities in China have experienced or are facing the task of expanding, adjusting, merging and rebuilding, relocation, and so on. ${ }^{[1]}$ Wuhan Polytechnic University is no exception.

Changqing campus of Wuhan Polytechnic University has been developed more than 20 years in the effects of many unanticipated factors. A campus is not only a place for teaching and life, but the education environment. It should make students experience the growth of the personality and the psychological. It should be positive, full of knowledge and interesting. ${ }^{[2]}$ Nevertheless, accompanied with the development, some problems have occurred to Changqing campus and have weakened the vitality. Significantly, they have become more harmful to the healthy development of the university. For instance, a small part of campus are usually crowed with people while others are unpopular.

To find out how exactly the problems are, first, we decided to embark on traffic investigation and questionnaire ${ }^{[3][4]}$. Secondly, works above were carried out. Then, the data was analyzed to be helpful to master how the unbalanced distribution of people was. After that, we have tried to find the reasons and solutions. Finally, some suggestions for the strategy of campus' reconstruction planning are put forward to.

In the traffic investigation, we adopted eight observation points, including all entrances to the campus and four points in the campus' main roads. We observed for 15 days and recorded 15 minutes for the interval from 7:30 am to $9: 00 \mathrm{pm}$.

In the questionnaire, we took back 287 questionnaires available, which had sixteen questions.

Here we only focus on the traffic investigation, just using some results from questionnaire.

\section{The STATUS QuO OF CHANGQING CAMPUS}

The development of Changqing campus of Wuhan Polytechnic University has experienced mainly four stages. The first stage is the original campus constructed since the mid of 1990s (Figure 1.), and then merged with a health school, which is adjacent to the football school and on the eastern side of the campus (Figure 2.). The third stage is the cooperation with non-governmental sectors, which has provided Changqing apartments as part of students' accommodation (Figure 3.). The fourth has cooperated partial with the soccer school, which is located between the original campus and the original heath school (Figure 4.). In short, the land shape of Changqing campus at present is extremely irregular as shown in Fig .4.

In 2004, the new campus of Wuhan Polytechnic University named Jinyinhu campus began to construct and put into use with the following year. Some colleges of the university have gradually moved to Jinyinhu campus from Changqing campus. Corresponding to the moving, the number of students in Changqing campus began to decrease, and finally to determine the future capacity of about 7000 people. 


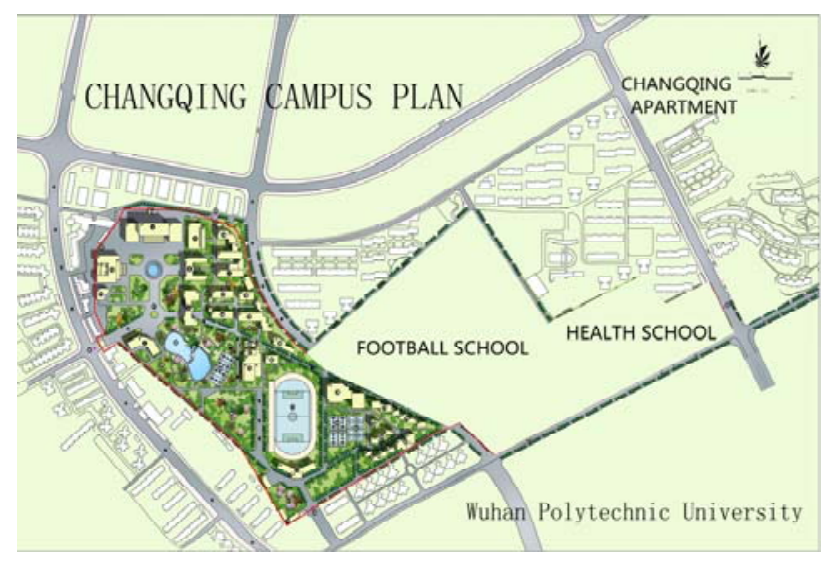

Figure 1. Original campus ( Stage one).

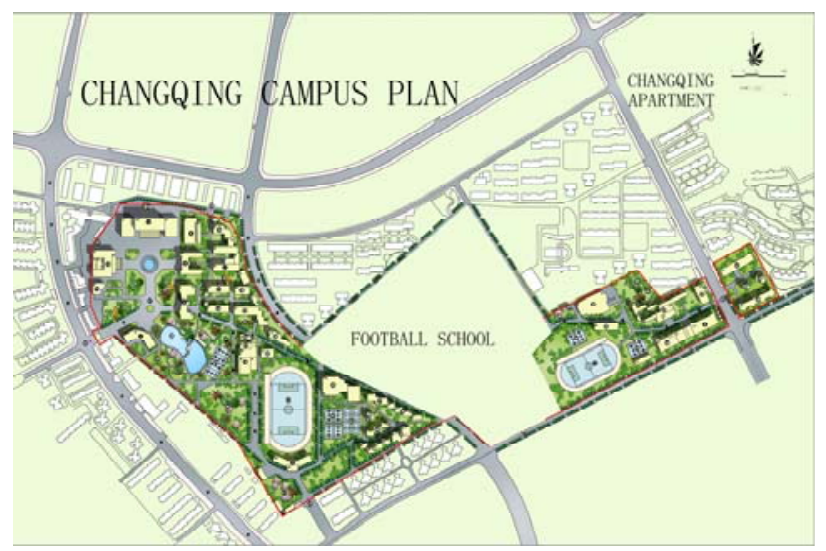

Figure 2. Merging with a healthcare school (Stage two).

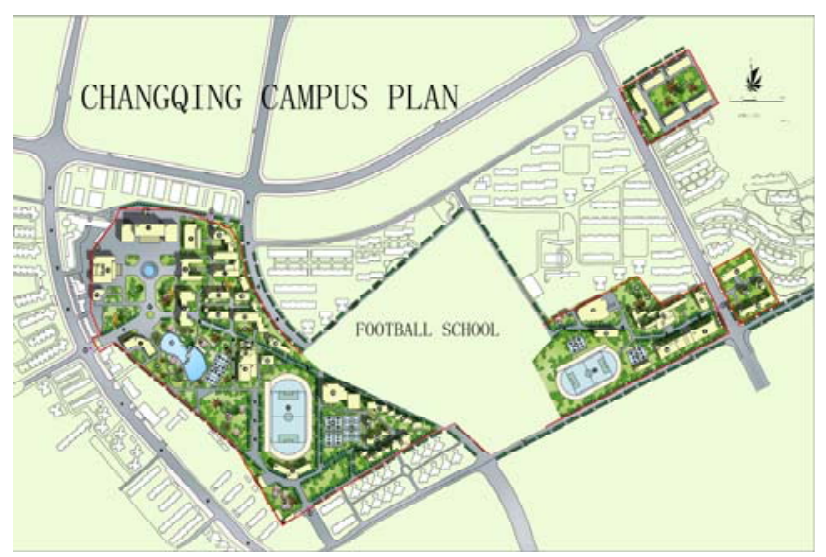

Figure 3. Cooperation with Changqing apartments(Stage three).

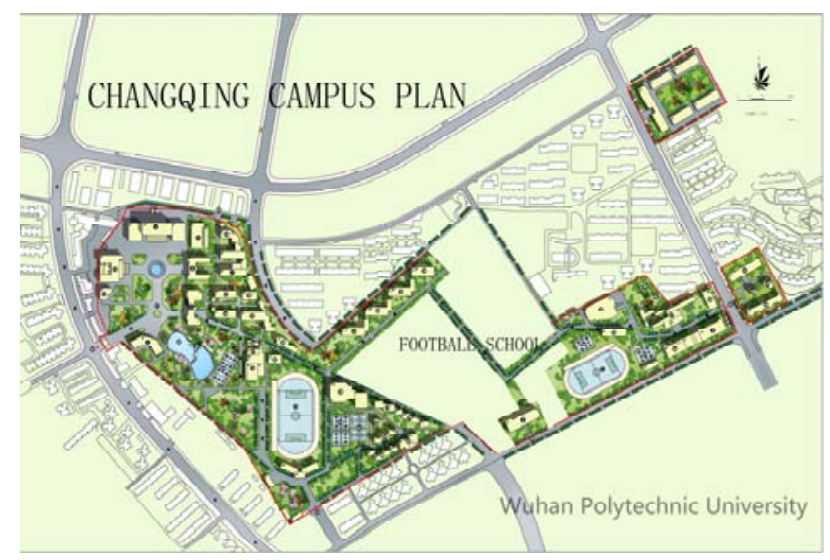

Figure 4. Collaboration with a soccer school (Stage four).
As a concern, Changqing campus have become depressed in many places and the energy has been no longer. This phenomenon is obviously unusual and should not appear in such a small campus which has been in continuous construction and reconstruction with the improvement of material conditions.

\section{The InVESTIGATION ON TRAFFIC DistRIBUTION}

The survey included three types which are motor vehicles, non-motorized vehicles and walking traffic. The results showed that the campus transportation was mainly on the pedestrian transport. So, here what we discuss focuses on the change in pedestrian transport.

The investigation, as we thought, the traffic distribution in the campus, as well as in the entrances to the campus, was extremely uneven. The specific was introduced next from the two aspects.

\section{A. Traffic Survey in the Campus' Main Roads}

The survey has been carried out in four main roads in the campus. Four observation points are shown in Fig .5, and the data is plotted in line graph (Graph 1.).

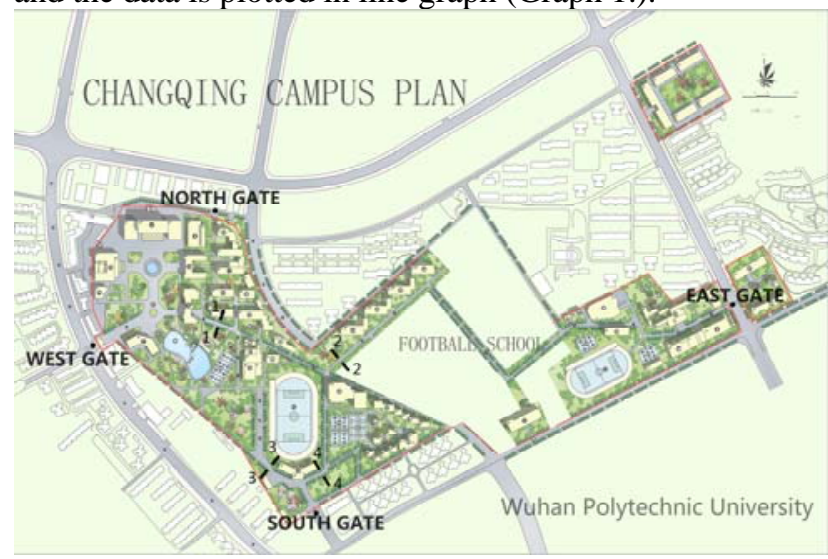

Figure 5. Eight observation points on traffic.

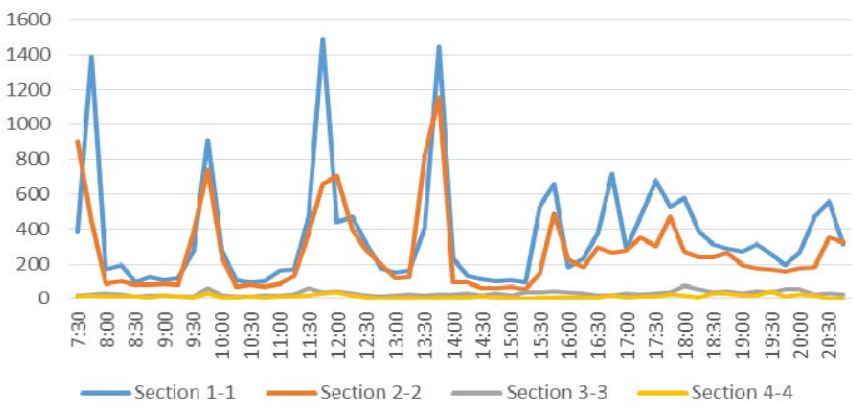

Graph 1. Traffic of four points in the main roads.

In Graph .1, the horizontal axis is time, initially expressed by 15 minutes for intervals, here only showed to 30 minutes for intervals due to space limitations. The vertical axis is the number of people in every 15 minutes.

From Fig .5 and Graph .1, it can be seen that a part of main roads in the campus undertake the main traffic while others are hardly shared. The traffic mostly concentrates on the main road where Section 1-1 and Section 2-2 located. In addition, there is a typical characteristic of the traffic on that road which is directly related to students' 
class schedule. The traffic usually reaches its peak at the time before and after classes, such as 7:45-8:00am, 9:4510:00am, 11:45-12:00, and 1:45-2:00 pm, and falls at the time during classes, such as 8:00-9:30 am, 10:00-11:30am, 2:00-3:30 pm. During the day, the traffic fluctuates significantly, with the peak number reaching 1448 people per 15 minutes which is around 15 times as high as the lowest number (only 91 people per 15 minutes). In the evening, the gap between the peak and the lowest point narrows considerably with the peak lowering and the lowest flow higher than those in the days respectively.

As another major artery in the south of the campus, its traffic flow is negligible compared with the previous. The traffic at Section 3-3 and 4-4 often only has a few people, even 2 people, and the max number is 75 people which is at Section 3-3 between 6:00 pm and 6:15 pm.

Overall, the traffic on the two main roads in the campus is extremely unbalanced.

\section{B. Investigation on the Traffic in the Entrances to the Campus}

The campus has four entrances, which are West Gate (also called Front Gate), North Gate, South Gate and East Gate (Figure 5). The investigation results on the traffic of four gates are shown as following (Graph 2.).

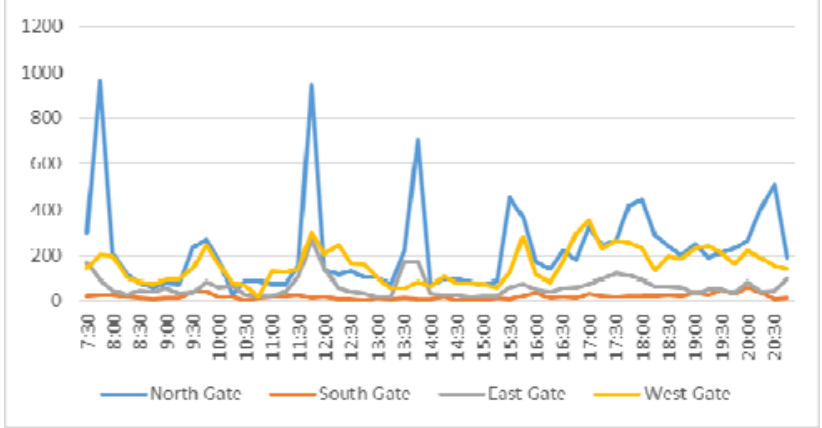

Graph 2. Traffic in the four entrances to the campus

It is clear from the Graph .2 that the traffic of North Gate is the most noticeable and is far higher than that of other three gates. It has a similar characteristic to the traffic of Section 1-1 and Section 2-2 on the main road in the campus. The traffic fluctuates considerably over the 13 hours. Between 7:30 am and 7:45 am the number of traffic of North Gate stands at 301 people. Then in the next a quarter of an hour the figure rises dramatically, peaking at 964. After that, the figure drops rapidly, reaching 60 within 8:45-9:00 am. The period between 9:30 am and 10:15 am experiences a slight rise in the traffic, with the number reaching 270 in 9:45-10:00am. The figure remains stable at just under 90 people over the following about two hours. Then the number of traffic sees a sharp increase, with the figure reaching 944 in 11:45am-12:00. After 12 o'clock, the figure falls again, and remains around 100 people before 1:30 pm. The period from 1:30 pm to 2:00 pm experiences anther rise, with the number reaching 703 people, but declines again in the next one and half an hours. After $3: 30 \mathrm{pm}$, the figure fluctuates between just above 400 to about 200 people, ending at 194 people in 8:459:00pm.
The traffic of West Gate and East Gate has a similar characteristic to that of North Gate, just companied with less gap between the peak and the lowest point. Specific to West Gate, after 3:45 pm, the traffic flow shows roughly the same to that of North Gate. By contrast, the traffic of South Gate is consistently lower than 60 people, with the figure only being around 20 in most of time.

In short, the traffic of four entrances to the campus is quite different.

At last, when we look at Graph .1 and Graph .2 together, it is not hard to find that the traffic distribution is really uneven. If we divide the whole campus into three parts (Figure. 6), the traffic mainly concentrates on the north of the campus.

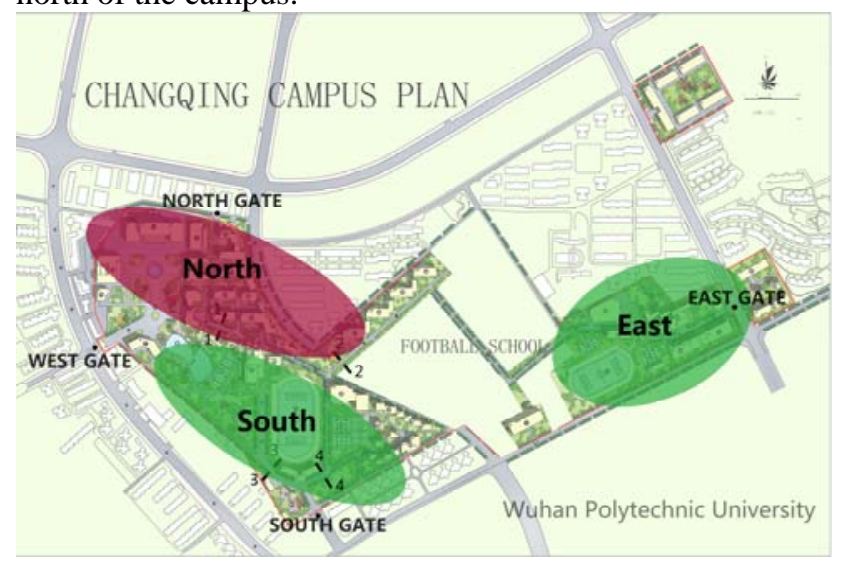

Figure 6. Zoning of the campus

\section{ANALYSIS OF REASONS}

\section{A. The Concentration Layout of Main Function Areas}

The northern campus has concentrated most of the traffic. What do we see in this area? Teaching buildings, laboratory buildings, library, students' dormitories and canteen. They can be summed up to the teaching area and students living area. If we continue to classify the other areas, we can get part of function zoning of the campus (Figure 7).

From Fig .7, Graph .1 and Graph .2, combining field observation, we can see that the traffic concentration is often located in the teaching area, students living area and the shortest roads contacting these two parts, such as Section 1-1 in the road connecting Guiyuan Apartment to Teaching Area, Section 2-2 in the road leading from Lvye Apartment to Teaching Area, North Gate and East Gate which are the usual ways for students from Changqing Apartment to Northern Teaching Area and Eastern Teaching Area.

Since the traffic is concentrated in the area of about $1 / 3$ of the campus, it can only say that the main function areas are too concentrated, especially to the teaching areas and students living areas.

Certainly, for another reason, we are in agreement that there is little choice in the road between the teaching area and the students living area, or that there is actually one. Due to another main road away from the two regions, it basically cannot play the role of streaming traffic, and this 
can be seen from the traffic in Section 3-3, Section 4-4, and South Gate.

\section{B. The Large Green Space without Attraction to People}

The large area of green space located in the south of campus is the main leisure area in the campus, but it does not meet the needs of college students. It has emphasized the greening function and cared less about the needs from the psychology and physiology of teachers and students just like other universities did ${ }^{[5][6][7][8]}$, not to mention to create a space for multi-level communication, study and recreation. That is to say, it is not consistent with the behavior of college students. For example, the matrix planting way brings a monotonous landscape, the lack of rest facilities makes people unable to stay here, and there is no even one big open space for group activities. All of these have caused that a large number of students would choose the park outside of the campus rather than this one. ${ }^{[9]}$ The design of this green space is actually a little bit failure in creating a natural place to students for recreation and leisure.

Anyway, on the one hand, the concentration of main function areas has brought people's excessive concentration in the north of the campus. On the other hand, the large area of green leisure space in the south is unpopular and almost idle. All of these have exacerbated the unbalanced distribution of people in campus.

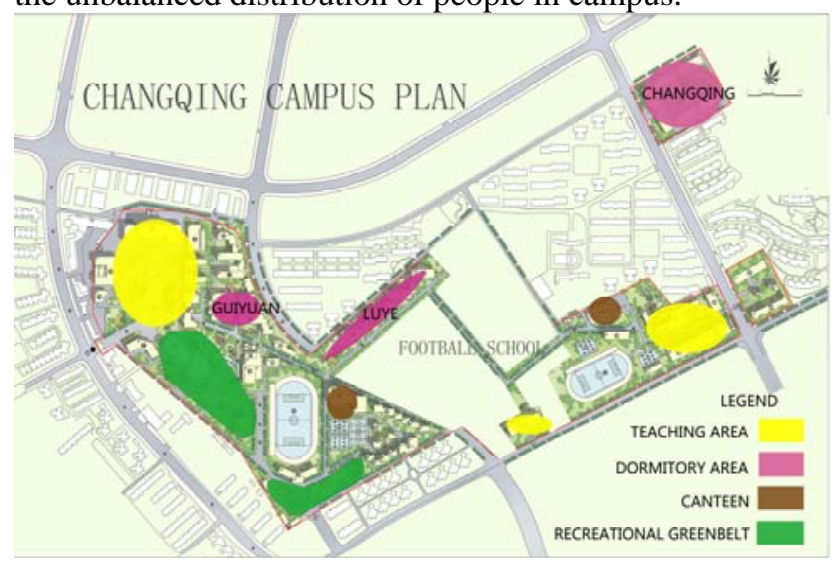

Figure 7. Part of function zoning of the campus

\section{STRATEGy FOR THE CAMPUS’ RESTRUCTIONG PLANNING}

A. Combined with the Development, Adjusting the Distribution of Some Facilities Which Attract a Large Number of People.

To change the unbalanced status, some facilities which attract many people need to be adjusted appropriately. This can be achieved by means of the development of university. For example, the campus has been proposed to construct a new building with a floor area of nearly 20 thousand square meters for one of colleges-College(Food Science and Engineering). This building has been planned to have lots of classrooms as well as offices, and it will inevitably has a significant impact on the redistribution of traffic in the campus. So, this building is recommended to set in the southern region where low traffic is. In addition, students have to take the dormitory as the start and destination of activities. If dormitories will be reconstructed or built new, they are recommended to be built near South Gate, and it is a good place on the south side of the basketball field.

With the help of constructing these buildings, the unbalanced traffic distribution will be relieved to some extent.

\section{B. Reshaping the Green Space in Accord with the Characteristic of College Students' Behavior}

We need to deeply analyze the psychological and behavioral habits of college students ${ }^{[9][10]}$, and to create a variety of green leisure space to meet their diversified requirements on learning, communication, rest, sports and so on. For example, open green space is built to be suitable for group activities, semi-open space is for rest, reading, watching, and overlooking, and private green space is for the young whisper, solitude and quiet rest.

In short, green space in university has not only the characteristics of the general public green space, but has the special characteristics with meeting the diversified needs of college students. This should be always clear in its design and construction.

\section{ACKNOWLEDGMENT}

Thanks to the support from Wuhan Polytechnic University.

Thanks to members of my team, who are Hua Bao, Xuhui Zhang, Gang Wu, Renjie Luo, Shuai Wang and Bing Ling.

\section{REFERENCES}

[1] Gao Jisheng, "Essentials of Contemporary Campus Planning" http://www.abbs.com.cn/newarch/read.php?cate=6\&recid=16133.

[2] "Analysis of construction plan in university campus", http://www.doc88.com/p-8975505977420.html

[3] Dai Fei, Zhang Jun-hua, "The Survey Methods in Planning and Design 1-Questionnaire Survey (Theory Part)”, Chinese Landscape Architecture, 2008, pp.82-87.

[4] Dai Fei, Zhang Jun hua, Wang Dong yu, "The Survey Methods in Planning and Design-Questionnaire Survey (Case Study Part)”, Chinese Landscape Architecture, 2008, pp.77-81.

[5] Zhu Lei, "Study on Campus Greenland Planning of Colleges and Universities”, Journal of Anhui Agricuture Science. 2007, pp.9923,9926.

[6] Li Lin, Study on Green Space Layout in Campus, Dissertation for the Degree of Master, Northeast Forestry University, 2009.

[7] Lu Hailan, Zhou Lingling, "Green Space Landscape Planning and Design in College and University Campus”, Journal of Chinese Urban Forestry, Vol. 11, 2013, pp.52-54.

[8] Shan Gao, The Humanization in Shared Outdoor Space in the High School Design, Dissertation for the Degree of Master, Nanchang Hangkong University, 2014.

[9] Zhao Huiyan, The questionnaire, unpublished.

[10] Bi Jing, Yang Zushan,“Analysis of campus green space planning and design”, Chinese Horticulture Abstracts, vol. 3, 2012, pp.103104.

[11] http://www.jianshe99.com/lunwen/gongchengjishu/ma2014071510 200836958562.shtml. 